\title{
Left atrial to left ventricle bypass for mitral valve stenosis
}

\author{
Anita Nguyen, MBBS, and Hartzell V. Schaff, MD
}

From the Department of Cardiovascular Surgery, Mayo Clinic, Rochester, Minn This work was supported by the Paul and Ruby Tsai Family.

Disclosures: Authors have nothing to disclose with regard to commercial support.

Received for publication Oct 22, 2018; accepted for publication Oct 27, 2018; available ahead of print Dec 14, 2018.

Address for reprints: Hartzell V. Schaff, MD, 200 First St SW, Rochester, MN 55095 (E-mail: schaff@ mayo.edu). J Thorac Cardiovasc Surg 2019;157:e361-2

$0022-5223 / \$ 36.00$

Copyright (c) 2018 by The American Association for Thoracic Surgery

https://doi.org/10.1016/j.jtcvs.2018.10.117

A 56-year-old man with radiation-induced heart disease presented with New York Heart Association class IV dyspnea due to severe calcific mitral valve stenosis (mean gradient, $16 \mathrm{~mm} \mathrm{Hg}$ ) (Figure 1, A). Twelve years before presentation, the patient underwent coronary artery bypass grafting, and 8 years later, he underwent transcatheter aortic valve implantation.

To relieve mitral valve obstruction, the patient underwent left atrial to left ventricle bypass with a valved conduit. Because of patent bypass grafts and extensive aortic calcification (Figure 1, B), the operation was performed through a left thoracotomy. During cardiopulmonary bypass with induced ventricular fibrillation, the proximal attachment of a 24-mm Dacron graft was sutured to the left atrium at the junction of the inferior pulmonary vein (Figure 1, C). A 23-mm bioprosthesis was sewn into the graft, which

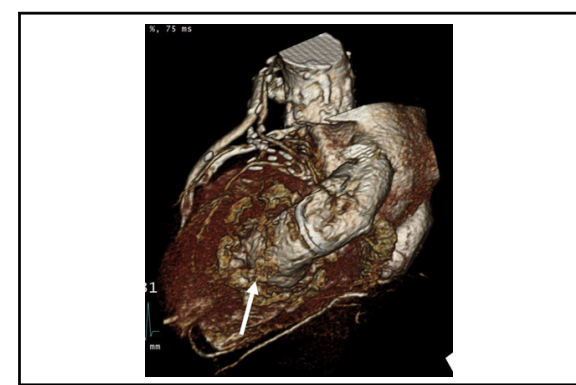

Left atrial to left ventricle bypass using a valved conduit.

\section{Central Message}

Left atrial to left ventricle bypass with a valved conduit is a surgical option for patients with severe calcific mitral valve stenosis.

See Commentary on page e 363.

was then anastomosed to a ventriculotomy on the lateral apical area of the left ventricle (Figure 1,D). He was discharged 10 days after surgery in satisfactory condition. 

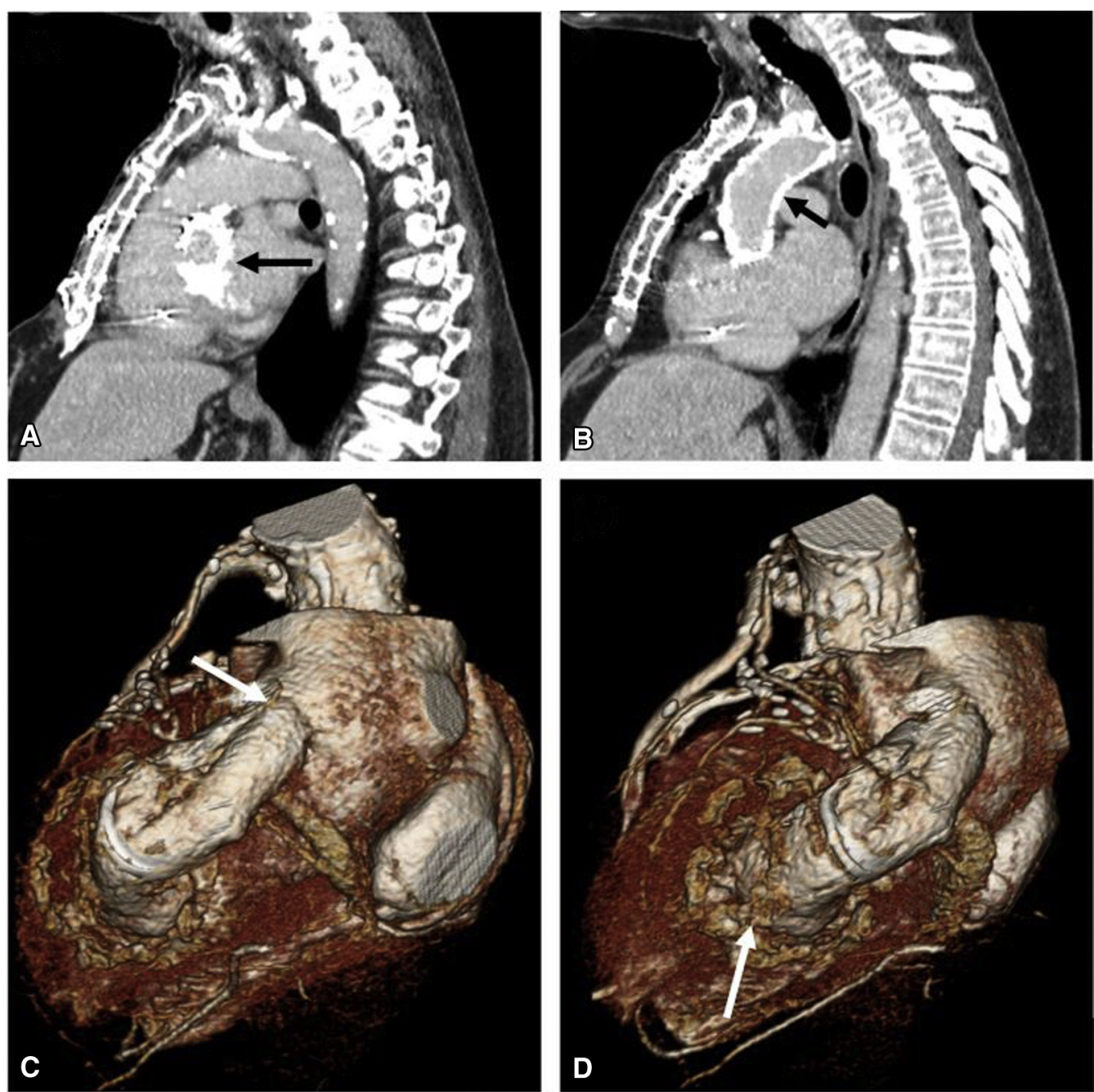

FIGURE 1. Pre- and postoperative computed tomography images of the patient. A, Severe mitral valve calcification. B, Calcified aorta. C and D, Postoperative 3-dimensional reconstruction showing attachments of the left atrial to left ventricle graft. 